\title{
Pembuatan Media Pembelajaran Bahasa Inggris Alfabet Berbasis Augmented Reality
}

Yudha Pradana', Adam Rizki Fadhlurahman

${ }^{1}$ Politeknik Negeri Media Kreatif

${ }^{2}$ Politeknik Negeri Media Kreatif

Email: 1yudha.pradana@polimedia.ac.id

INFORMASI ARTIKEL

Sejarah Artikel:

Diterima Redaksi: 28 Maret 2020

Revisi Akhir: 2 Juli 2020

Diterbitkan Online: 15 Juli 2020

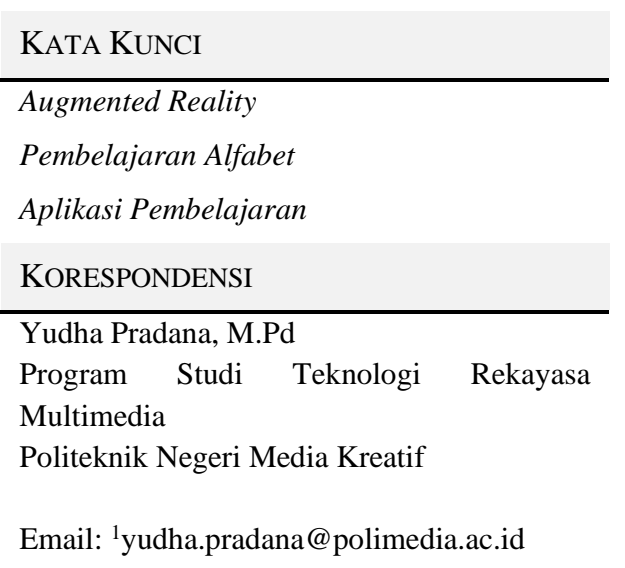

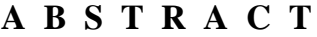

Penggunaan media belajar oleh guru dalam pembelajaran akan menentukan keberhasilan pencapaian tujuan pembelajaran baik tujuan instruksional maupun pencapaian pengetahuan oleh siswa. Hal tersebut juga berlaku dalam pembelajaran bahasa Inggris yang salah satu tujuannya mengenalkan objek pembelajaran bagi siswa dalam bahasa Inggris. Namun masih terbatasnya media pembelajaran alternatif yang digunakan selain media pembelajaran berupa buku atau gambar.

Pembuatan aplikasi augmented reality ini untuk mengoptimalkan pembelajaran bahasa Inggris pada materi pengenalan alfabet. Tahapan pembuatan apllikasi terdiri dari praproduksi, produksi, dan pascaproduksi. Melalui pengujian aplikasi ini dapat digunakan secara baik dan secara penggunaan memudahkan guru dan siswa dalam belajar bahasa Inggris.

\section{PENDAHULUAN}

Perkembangan teknologi informasi salah satunya dengan hadirnya augmented reality dapat dijadikan sebagai peluang dalam menghadirkan media belajar oleh guru khususnya dalam pelajaran bahasa Inggris. Raajan (2014) mengemukakan bahwa augmented reality pertama kali digunakan pada tahun 1957-1962 oleh Norton Heilig berupa sebuah simulator yang diberi nama sensorama yang dapat mensimulasikan visual, getaran, dan bau.

Manuri dan Sanna (2016) mengatakan bahwa augmented reality merupakan salah satu bagian dari virtual environment yang memberikan gambaran kepada pengguna tentang penggabungan dunia nyata dengan dunia maya dilihat dari tempat yang sama dan memiliki tiga karakteristik, yaitu bersifat interaktif, menurut waktu nyata, dan berbentuk tiga dimensi.

Salah satu hal yang dapat dikembangkan melalui penggunaan media augmented reality dalam pembelajaran ialah untuk pembelajaran bahasa Inggris. Ilmawan Mustaqim dan Nanang Kurniawan (2017) menyimpulkan melalui penggunaan augmented reality sebagai media pembelajaran ialah guru dapat membuat media pembelajaran yang menyenangkan, interaktif, dan mudah digunakan, serta dapat menggantikan modul pembelajaran yang belum ada di sekolah dalam bentuk virtual atau maya.

Penggunaan augmented reality tentunya dapat membuat pembelajaran menjadi lebih interaktif bagi siswa. Artinya media yang digunakan bersifat interaktif. Temuan Andy Gohan Pardede (2014) bahwa media interaktif melalui augmented reality dapat meningkatkan metode flash card dengan pengajaran yang lebih tepat mengenai pengucapan/intonasi bahasa Inggris.

Temuan Dian Syafitri Chani Saputri (2017) juga menyebutkan bahwa Pembelajaran berbasis augmented reality adalah rangkaian kegiatan terstruktur dimana terjadi interaksi antara siswa, guru dan bahan belajar dengan memanfaatkan teknologi augmented reality pada suatu lingkungan belajar yang kondusif sehingga hasil belajar yang memenuhi tujuan pembelajaran dapat dicapai. Pembelajaran berbasis augmented reality dirancang dengan memperhatikan tujuan pembelajaran, perkembangan kognitif dan karakteristik siswa sehingga 
tercipta pembelajaran yang interaktif dan menarik yang dapat membantu siswa menguasai kosakata dalam bahasa Inggris.

Dari pemaparan-pemaparan di atas penulis tertarik untuk membuat augmented reality sebagai media pembelajaran bahasa Inggris. Diharapkan dengan adanya media pembelajaran tersebut dapat mepermudah pembelajaran dan pembelajaran menjadi lebih interaktif serta dapat meningkatkan minat belajar siswa.Pembuatan media augmented reality untuk pembelajaran bahasa Inggris?. Tujuan penulisan ialah untuk mengetahui pembuatan media augmented reality untuk pembelajaran bahasa Inggris. Batasan penulisan yang ditetapkan ialah:

a. Augmented reality dibuat untuk pembelajaran bahasa Inggris materi alfabet.

b. Konten yang dibuat ialah berupa pengenalan huruf dengan menghadirkan objek buah dan suara pelafalan huruf dalam bahasa Inggris.

c. Augmented reality dibuat untuk pembelajaran siswa Taman Kanak-kanak.

\section{PEMBAHASAN}

Sebelum membuat augmented reality ini, penulis menganalisis kebutuhan melalui pengumpulan data-data terkait agar apa yang hendak penulis buat sesuai dengan konteks kebutuhan yang diinginkan. Pengumpulan data dilakukan melalui observasi, wawancara, dan studi referensi. Selain itu penulis melakukan curah pendapat dengan pihak-pihak terkait untuk mendapatkan informasi sehingga memudahkan saat pengambilan keputusan mengenai apa yang akan diimplementasikan dalam pembuatan aplikasi ini.

Selain itu penulis juga menganalisis kebutuhan yang diperlukan dalam pembuatan aplikasi ini. Analisis kebutuhan fungsional berupa urgensi pembuatan aplikasi ini yang dapat dijadikan sebagai media pembelajaran alternatif dalam pembelajaran bahasa Inggris khususnya pada materi pengenalan alfabet. Analisis kebutuhan fungsional mencakup mengenai aplikasi yang diperlukan serta konten yang akan dimuat dalam aplikasi tersebut.

Analisis kebutuhan lainnya yang dilakukan ialah analisis kebutuhan non-fungsional berupa pemilihan perangkat-perangkat yang dibutuhkan agar pembuatan aplikasi ini dapat berjalan optimal. Analisis non-fungsional yang dilakukan berhasil menyimpulkan bahwa pembuatan aplikasi ini membutuhkan perangkat-perangkat sebagai berikut:

a. Kebutuhan perangkat keras berupa laptop dengan spesifikasi Processor Intel ${ }^{\circledR}$ Core $^{\mathrm{TM}}$ i5-8300H CPU @ 2.30GHZ, memori 8GB DDR4, sistem Operasi Windows 10, dan memiliki grafis GTX 1050. Selain itu dibutuhkan perangkat smartphone dengan spesifikasi sistem operasi android v 7.1 Nougat, memori 3 GB RAM, Internal 64 GB, dan ukuran layar 720 x 1280 pixels, 16:9 ratio, 267 ppi pixel density.

b. Kebutuhan perangkat lunak berupa:

- Adobe Illustrator CC 2018 untuk pembuatan asset, pembuatan sketsa awal, design marker, design user interface aplikasi, design booklet, pembuatan sketsa alfabet dan objek aplikasi.
- Unity sebagai untuk pembuatan sebuah aplikasi, karena sudah terdapat SDK dan JDK Vuforia Unity.

- Autodesk Maya 2017 untuk pembuatan objek Alfabet dan Objek lainnya dalam bentuk 3D.

Selain menganalisis kebutuhan fungsional dan nonfungsional, penulis juga melakukan analisis kebutuhan sistem yang akan ditampilkan dalam aplikasi. Analisis ini berguna untuk memberikan gambaran agar aplikasi yang dibuat mudah untuk digunakan dan sesuai dengan tujuan pembuatan aplikasi. Melalui analisis sistem maka diputuskan beberapa hal terkait yang perlu penulis lakukan seperti penyediaan tombol-tombol dengan fungsi tertentu dan pemilihan penentuan desain aplikasi.

Pembuatan aplikasi ini terdiri dari tahap praproduksi, tahap produksi, dan tahap pascaproduksi. Ketiga tahapan tersebut saling berkaitan satu sama lainnya. Tahap praproduksi mencakup kegiatan pencarian ide dan curah pendapat dengan guru mengenai aplikasi yang akan dibuat. Disimpulkan bahwa aplikasi yang akan dibuat ialah mengenai pembelajaran bahasa Inggris pada materi pengenalan alfabet dan disesuaikan dengan pendekatan pembelajaran dan karakter siswa. Maka diputuskan aplikasi berisi mengenai pengenalan alfabet dengan menampilkan ilustrasi buah dan cara penyebutan huruf pada setiap alfabet yang ditampilkan.

Salah satu yang dilakukan dalam tahap praproduksi ialah merancang use case diagram untuk menggambarkan sebuah interaksi antara satu atau lebih aktor dengan sistem informasi yang akan dibuat serta untuk mengetahui fungsi apa saja yang ada di dalam sebuah sistem dan siapa saja yang berhak menggunakan fungsi-fungsi tersebut.

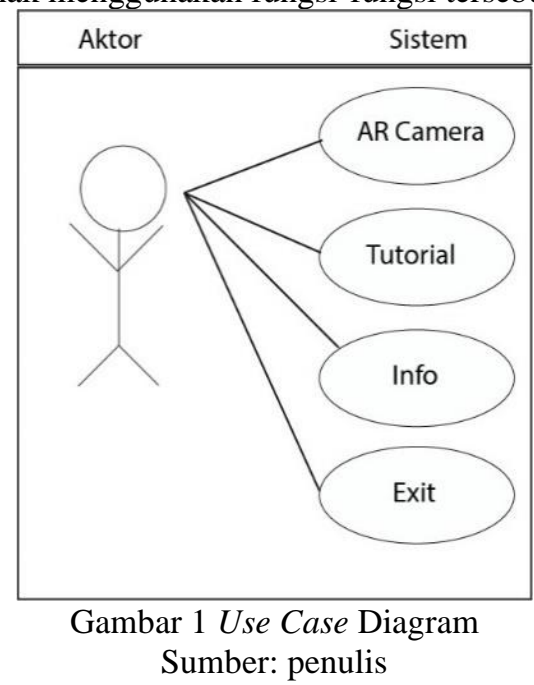

Kegiatan produksi berupa pembuatan konten dan segala sesuatu yang berhubungan dengan aplikasi seperti perancangan dan pembuatan asset, mendesain user interface, pembuatan marker, pembuatan objek yang ditampilkan dalam aplikasi, serta pemilihan dan pembuatan audio. Pada tahap ini juga dilakukan pemograman dan build aplikasi.

Asset aplikasi berupa buah-buahan yang terkait dengan huruf yang ditampilkan sebagai objek dalam aplikasi ini. Melalui pemilihan asset diharapkan memberikan kesan menarik bagi siswa dan sesuai dengan apa yang mereka ketahui dalam kehidupan sehari-hari. 


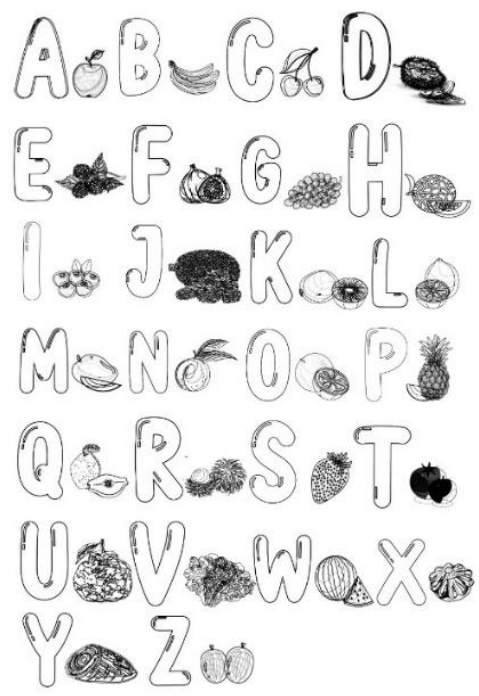

Gambar 2 Sketch Asset Aplikasi Sumber: penulis

Karakter siswa sebagai salah satu objek dalam aplikasi ini memberikan gambaran sebagai siswa yang belajar dan disesuaikan dengan karakteristik pengguna aplikasi.
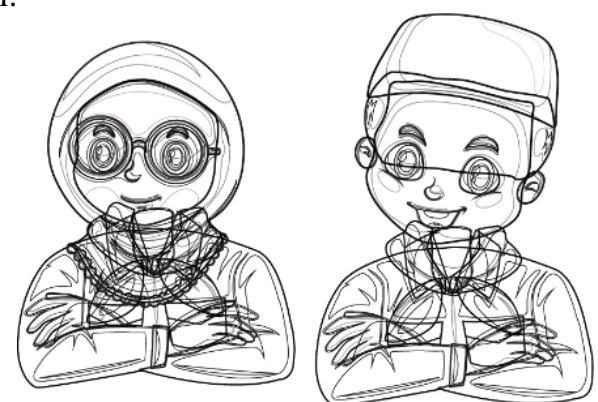

Gambar 3 Sketch Karakter Siswa dalam Aplikasi Sumber: penulis

Selain itu dalam tahapan ini juga dibuat halaman menu utama, halaman tutorial penggunaan aplikasi, halaman informasi, dan halaman augmented reality. Halaman menu utama berisikan pilihan-pilihan bagi pengguna dalam menggunakan aplikasi ini. Pilihan tersebut berupa tombol penggunaan AR Camera, Tutorial, dan Info.

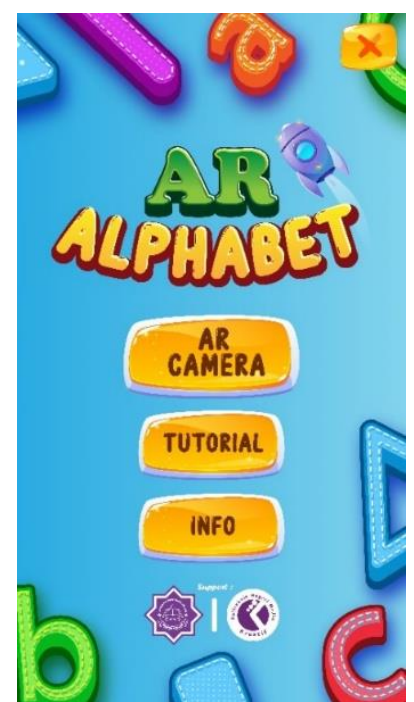

Gambar 4 Halaman Menu Utama Sumber: penulis

Halaman tutorial berisikan informasi penggunakan aplikasi. Melalui halaman ini pengguna akan diberikan pengetahuan mengenai cara menggunakan aplikasi.

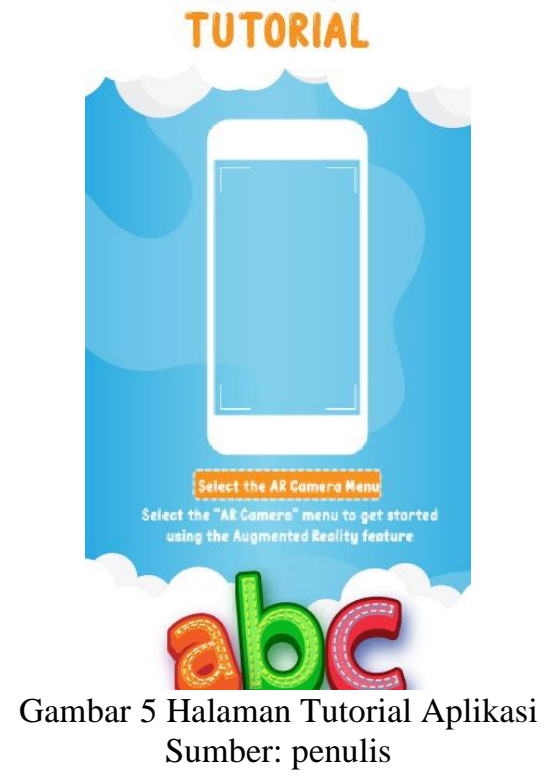

Halaman informasi berisikan tentang informasi tentang aplikasi, baik infomasi berupa penjelasan dari aplikasi tersebut maupun informasi pembuat aplikasi. 


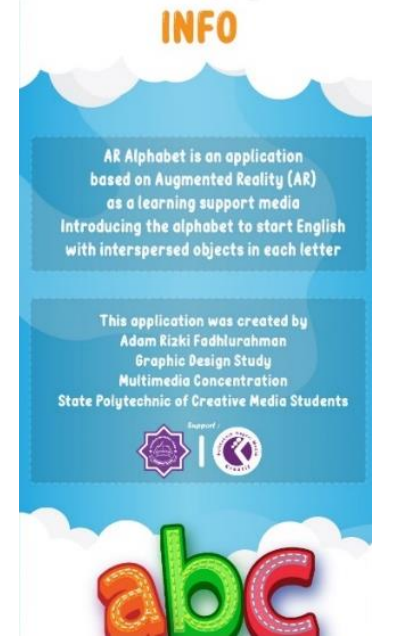

Gambar 6 Halaman Informasi Sumber: penulis

Halaman AR Camera merupakan tampilan inti dari aplikasi ini yang akan menampilkan huruf alfabet dan objek sebagai media pembelajaran, serta tombol voice untuk mendengaran secara langsung pengejaan huruf dan objek yang ditampilan.

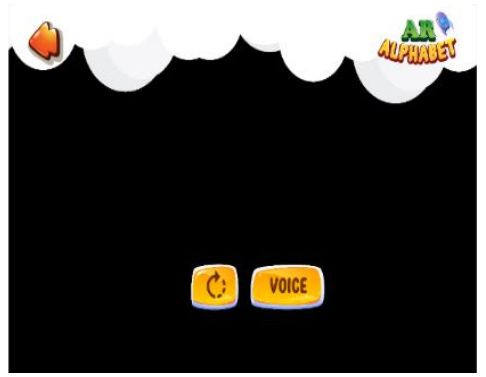

Gambar 7 Halaman AR Camera Sumber: penulis

Booklet dalam aplikasi ini berfungsi sebagai marker untuk menghubungkan objek yang ada dalam booklet dan menampilkan augmented objek sesuai dengan objek yang dipilih. Isi booklet ialah objek huruf dan buah yang berkaitan dengan huruf serta berisi asset karakter siswa sekolah.

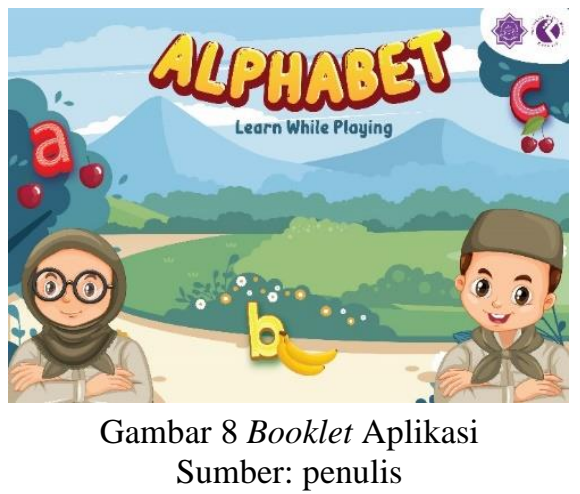

Tahap pascaproduksi ialah tahap setelah aplikasi seleai dibuat. Pada tahap ini dilakukan testing untuk mengetahui sejauh mana aplikasi akan berjalan baik atau masih mengalami hambatan atau jika masih ada kekurangan. Testing dilakukan dengan cara menggunakan empat buah smartphone dengan versi operasi sistem yang berbeda untuk mengetahui kecepatan camera proses dan proses berjalannya aplikasi. Selain itu pengujian juga dilakukan untuk mengetahui visibility aplikasi dari segi pengalaman pengguna sehingga aplikasi dapat disimpulkan sesuai dengan tujuan perancangan atau masih ada yang harus diperbaiki.

\section{PENUTUP}

\section{Kesimpulan}

Pembuatan aplikasi augmented reality ini untuk mengoptimalkan pembelajaran bahasa Inggris pada materi pengenalan alfabet. Tahapan pembuatan apllikasi terdiri dari praproduksi, produksi, dan pascaproduksi. Melalui pengujian aplikasi ini dapat digunakan secara baik dan secara penggunaan memudahkan guru dan siswa dalam belajar bahasa Inggris.

Saran

Dari hasil pembuatan aplikasi, penulis memberikan saran untuk pengembangan aplikasi serupa di masa datang sebagai berikut:

1. Objek yang dibuat dalam augmented reality dapat ditambahkan fitur zooming pada video lalu objek dapat dispesifikasikan ke dalam materi yang diinginkan. Sehingga materi yang disampaikan pada satu objek dapat lebih spesifik lagi.

2. Objek interaktif bisa ditambahkan menjadi tiga dimensi sehingga bisa lebih menarik minat dari siswa.

3. Objek yang dibuat bisa ditambahkan fitur latihan untuk mengulang kembali materi atau mengukur penguasan siswa terhadap materi.

\section{DAFTAR PUSTAKA}

Manuri, F., dan Sanna, A. 2016. A Survey on Applications of Augmented Reality. Advances in Computer Science: An International Journal, 18-27.

Mustaqim, I. dan Nanang Kurniawan. 2017. Pengembangan Media Pembelajaran Berbasis Augmented Reality. Jurnal Edukasi Elektro, Vol. 1, No. 1, 36-48.

N.R Raajan. et al. 2014. A Review on: Augmented Reality Technologies, System and Applications. Jurnal Asian Network for Scientific Information. 14 (14), 1485-1486.

Pardede, A.G. 2014. Pembangunan Aplikasi Media Pembelajaran Kosa Kata Bahasa Inggris bagi Anak Menggunakan Augmented Reality Berbasis Android. Skripsi pada Fakultas Teknologi Industri Universitas Atma Jaya Yogyakarta. Yogyakarta: tidak diterbitkan.

Saputri, D. S. C. 2017. Penggunaan Augmented Reality untuk Meningkatkan Penguasaan Kosa Kata dan Hasil Belajar. Jurnal Jutisi, Vol. 6, No. 1. 


\section{BIODATA PENULIS}

\section{Nama Mahasiswa}

Biodata penulis, dituliskan secara singkat (maksimal 100 kata) dan boleh disertai dengan foto. Tinggi maksimal foto adalah 2,5 $\mathrm{cm}$ dengan lebar menyesuaikan.

\section{LAMPIRAN}

Lampiran yang perlu disampaikan sebagai pendukung artikel, dituliskan setelah Biodata penulis. Maksimal sebanyak 4 (empat) halaman, diizinkan untuk bagian lampiran. Bila menyertakan tabel, gambar, atau persamaan matematika, juga diberi nomor berurutan 